\title{
EL DERECHO URBANÍSTICO ESPAÑOL. INTRODUCCIÓN A UNA VISIÓN CRÍTICA DESDE LA PERSPECTIVA DE LA ESCUELA AUSTRIACA DE ECONOMÍA
}

\author{
JOAQUÍN AZPITARTE*
}

\begin{abstract}
Resumen: El presente artículo pretende mostrar de una forma introductoria como el derecho urbanístico español se fundamenta en principios muy alejados de la función empresarial, que permite que el ciudadano desarrolle sus facultades vitales plenamente y en libertad. Estructurado en un extenso cuerpo legal, el articulado que regula el crecimiento de la ciudad, afecta de forma inexorable a su desarrollo económico y al de sus habitantes. La ciudad moderna española es una ciudad íntegramente planificada. Se trata de un caso evidente del «abuso de la razón» que denunciaba Hayek. Todos los viales, zonas edificatorias, volúmenes y usos permitidos están ya contemplados y planificados por la administración pública a través de los llamados Planes Generales de Ordenación y sus redactores.
\end{abstract}

Palabras clave: Orden espontáneo, planificación, limitación de los recursos, legislación urbanística, eficiencia dinámica, cálculo económico, propiedad.

Clasificación JEL: B53, D43, D61, D73, H54, H76, H82, H83, K1 1, L38, O21, O38, P14, P25, P26, P35, R14, R21, R31, R38.

Abstract: This paper provides an introductory analysis of the principles that inform urban planning in Spain, and shows how far removed it is from the principles of entrepreneurship, which promote freedom and the development of the potentialities of the individual. The massive body of legislation regulating city development in Spain has proven fatal to the economic prosperity of its citizens. Today, cities in Spain are the product of the most comprehensive

* Máster en Economía de la Escuela Austriaca. Universidad Rey Juan Carlos de Madrid.

Procesos de Mercado: Revista Europea de Economía Politica

Vol. IX, n. ${ }^{-}$1, Primavera 2012, pp. 73 a 109 
planning imaginable (an «abuse of reason», to quote F.A. Hayek). From town planning to zoning and building volumes, every aspect is laid out in the Planes Generales de Ordenación (Comprehensive Urban Development Plans) drafted jointly by politicians and developers.

Key words: Spontaneous order, planification, limitation of resources, urban legislation, dynamic efficiency, economic calculus, property.

JEL Classification: B53, D43, D6 1, D73, H54, H76, H82, H83, K1 1, L38, O21, O38, P14, P25, P26, P35, R14, R21, R31, R38.

\section{I}

\section{LA LEGISLACIÓN URBANÍSTICA}

Una legislación eficiente es condición necesaria para el funcionamiento de una ciudad en convivencia y libertad. «El estado debe proteger en lo posible a todo miembro de la sociedad de la injusticia y la opresión de cualquier otro miembro». ${ }^{1}$ Para ello debe solventar los conflictos con acierto, rapidez y eficacia y asegurar la protección de la vida, de la propiedad privada y de los contratos. La legislación debe ser flexible en su aplicación, rehuyendo tentaciones organizativas en favor de la aplicación de la costumbre y de la jurisprudencia. Solo así las leyes podrán adaptarse al cada vez más veloz mundo en el que vivimos y a la infinidad de conflictos que en él surgen, de forma previsible y sin bloquear los fines y objetivos de los ciudadanos. Una legislación positiva, tarde o temprano se verá torpe e incapaz de seguir el ritmo del progreso. Tal y como indica con acierto el profesor Martínez Meseguer «De esta forma, y movida por la función empresarial, comienza a crecer y a desarrollarse una red de relaciones de tipo comercial cada vez más densa, y que se ve facilitada, tanto por un respeto mínimo a la libertad de decisión individual, como por el incipiente concepto de propiedad privada, posibilitando ambos el inicial desarrollo de la civilización y del mercado.»²

\footnotetext{
1 Infantino (2000), p. 90.

2 Martínez Meseguer (2009).
} 


\section{II \\ EL TERRITORIO EDIFICABLE. LA AUTO LIMITACIÓN DE LOS RECURSOS}

Si contemplamos el territorio a vista de pájaro podemos percibir como la ciudad actual constituye una aglomeración aislada, cuyo área esta definida por un muro virtual que la delimita. En su interior se acumula la ciudad mientras que extramuros no es posible, en general, la edificación. Se configura así una ciudad con aparentes similitudes formales y funcionales con la medieval pero cuyo aislamiento no se deriva de la seguridad militar que en aquella se imponía. Este límite artificial es consecuencia esta vez de un mandato legislativo que coercitivamente impide a los ciudadanos utilizar su propiedad para edificar más allá del llamado Suelo Urbano. Nos encontramos con que fuera de los límites de esta muralla virtual no es posible la edificación residencial y las pocas construcciones permitidas sufren de grandes restricciones edificatorias, tanto a través de limitaciones de uso como de volumen. Un visitante exterior probablemente quedaría sorprendido al ver que las personas viven hacinadas en espacios premeditadamente limitados cuando el territorio vacío se extiende a lo largo del horizonte. Si el objeto de la economía es estudiar la correcta distribución de los recursos escasos para satisfacer las necesidades del ser humano, y si la lucha del ser humano es la dura lucha por hacer menos escasos todos esos recursos que el planeta nos ofrece, resulta paradójico que sea el propio ser humano el que limite sus propios recursos contribuyendo de esta forma a endurecer las condiciones de vida de sus semejantes. Esta primera limitación del territorio edificable vacía de contenido la propiedad. Así lo reconoce ya la propia Constitución Española en su artículo $33^{3}$ otorgándote el derecho de propiedad y retirándotelo en el mismo artículo. Vaciadas de contenido las distintas propiedades que se extienden a lo largo del territorio son un rico recurso del que el estado nos ha desposeído. Es cierto que ni la propiedad ni los

\footnotetext{
3 Constitución Española. Artículo 33: «1. Se reconoce el derecho a la propiedad privada y a la herencia. 2. La función social de estos derechos delimitará su contenido, de acuerdo con las leyes.»
} 
contratos son derechos absolutos, pero su limitación debe surgir del conflicto y de su correspondiente juicio en la búsqueda de la verdad jurídica, pero nunca de mandatos imperativos.

\section{III \\ EL ORDENAMIENTO URBANÍSTICO. UN ERRONEO CONCEPTO DE ORDEN.}

El derecho urbanístico español ${ }^{4}$ es en su práctica totalidad un derecho dictado. Las diferentes leyes que estructuran el llamado «ordenamiento» urbanístico español aportan un orden exógeno diseñado en un intento de ajustarlo a un patrón considerado como óptimo para su funcionamiento. Se trata de un orden creado por un conjunto reducido de personas que intentan racionalizar, hacer más eficiente se entiende, el sistema a ordenar. La finalidad última no está realmente clara. En general las distintas leyes españolas justifican este «ordenamiento» consagrándolo a fines tan difusos y fuera de su alcance como: la «función social», 5 la actividad de ordenación como «función pública», ${ }^{6} \mathrm{el}$ «desarrollo sostenible», ${ }^{7}$ la "preservación de la biodiversidad y de la

4 Tomamos a título de referencia y de ilustración una de las comunidades autónomas españolas, en este caso la Canaria.

5 Decreto Legislativo $1 / 2000$, de 8 de mayo, por el que se aprueba el Texto Refundido de las Leyes de Ordenación del Territorio de Canarias y de Espacios Naturales de Canarias. «Artículo 1. Objeto de la Ley: El presente Texto Refundido tiene por objeto en la Comunidad Autónoma de Canarias: 3. Definir el régimen jurídico urbanístico de la propiedad del suelo y vuelo, de acuerdo con su función social.»

6 Decreto Legislativo $1 / 2000$, de 8 de mayo, por el que se aprueba el Texto Refundido de las Leyes de Ordenación del Territorio de Canarias y de Espacios Naturales de Canarias. «Artículo 2. Actividad de ordenación. La actividad de ordenación de los recursos naturales, territorial, del litoral y urbanística es una función pública y corresponde, en el ámbito de sus competencias, a la Comunidad Autónoma, a las Islas y a los Municipios.»

7 Decreto Legislativo 1/2000, de 8 de mayo, por el que se aprueba el Texto Refundido de las Leyes de Ordenación del Territorio de Canarias y de Espacios Naturales de Canarias. «Artículo 2. Actividad de ordenación. La actividad de ordenación de los recursos naturales, territorial, del litoral y urbanística es una función pública y corresponde, en el ámbito de sus competencias, a la Comunidad Autónoma, a las Islas y a los Municipios. 2. La ordenación de los recursos naturales de Canarias se orientará: A la búsqueda y consecución de un desarrollo sostenible.» 
singularidad y belleza de los ecosistemas y paisajes», la «mejora de la calidad de vida de las comunidades locales», la "preservación de la biodiversidad», el «desarrollo racional y equilibrado», la «armonización de requerimientos del desarrollo social», la "promoción de la cohesión e integración sociales», ${ }^{8}$ etc. Y lo hace en base a mecanismos tan simples como criterios de repetición y ordenación física de los usos, aspecto estético, edificabilidades, y demás parámetros territoriales, ignorando que la complejidad de la interacción humana responde a criterios praxeológicos en los que ya están implícitos fenómenos como la empresarialidad, el sentido de la estética, el compromiso individual con el medio ambiente, el cuidado del ornato, etc.

$Y$ es que, siguiendo al profesor Martínez Meseguer la ley no debería perseguir crear un determinado orden, sino poner las bases para que el propio orden espontáneo crezca y evolucione en un contexto de libertad. ${ }^{9}$

El Orden sin Plan ${ }^{10}$ nace necesariamente de la convivencia y de la generación de un orden espontáneo. Este orden espontáneo se apoya a su vez en una serie de instituciones que nunca pudieron crearse de forma planificada: el derecho, la moral, las tradiciones, la religión, el dinero, etc. ${ }^{11}$ Así es como se construyó la ciudad en sus orígenes. Bajo unas formas de actuar íntimamente ligadas con las instituciones que cobijaba y que la hicieron posible. La ciudad fue en sus comienzos fruto de la natural interacción de los seres humanos que la poblaban. Allí donde se asentaban para comerciar nacía la plaza, allí por donde transitaban, la calle, y en donde era posible guarecerse de las inclemencias, la casa. Mucho ha cambiado el panorama con el transcurso de los años. Actualmente la planificación manda. Una falsa percepción nos hace identificar planificación con progreso. Pero no nos engañemos, uno no siempre es fruto de la otra.

8 Decreto Legislativo 1/2000, de 8 de mayo, por el que se aprueba el Texto Refundido de las Leyes de Ordenación del Territorio de Canarias y de Espacios Naturales de Canarias.

9 Martínez Meseguer (2009), p. 14.

10 Infantino (2000).

11 Martínez Meseguer (2009). 


\section{IV \\ LA HIPERINFLACIÓN DE LA LEGISLACIÓN URBANÍSTICA O LA IMPOSIBILIDAD DE INTENTAR REGULAR LA COMPLEJIDAD}

En una tendencia contraria a la de un orden espontáneo y en un vano intento por regular toda actuación humana los legisladores españoles han creado una red normativa que reduce a mínimos todo movimiento empresarial. Nos encontramos con un mar de regulaciones fruto de una esquizofrenia que persigue la labor imposible de regularlo todo y cuyas consecuencias para la realidad empresarial son impredecibles y fatales para el progreso y la productividad.

Se dictan unas leyes que crean unas disfunciones que nos llevan a otras que, pretendiendo minimizarlas, crean a su vez otras disfunciones. Así por ejemplo podemos observar como la limitación del territorio edificable provoca que, reducido drásticamente la cantidad de suelo edificable, haya una tendencia desmesurada hacia la colmatacion del territorio urbano. Posteriormente esa tendencia a la hiper densidad se intenta controlar mediante más leyes coercitivas que intentan evitar las grandes superficies edificables. Y todas estas normas se dictan sin realización posible del cálculo económico necesario y por lo tanto sin la mínima eficiencia exigible.

En palabras del profesor Huerta de Soto «El deseo voluntarista de "ordenar" la sociedad vía mandatos coactivos es esencialmente generador de desorden. Paradójicamente, la generalizada descoordinación a nivel social muy a menudo se utiliza como un pretexto para justificar ulteriores dosis de socialismo, Queda, por tanto, explicada la irresistible tendencia del socialismo hacia el totalitarismo, (se produce una espiral hacia el totalitarismo empujado por los desajustes que ocasiona el propio socialismo).» ${ }^{12}$

Como intentaremos explicar más adelante, la multiplicidad de factores que influyen en la eficiencia, los objetivos y los fines

\footnotetext{
12 Huerta de Soto (2010), p. 112
} 
de cada uno de los habitantes de la ciudad y la clase de información ${ }^{13}$ manejada en la interacción social hacen que la optimización mediante un órgano centralizado que lo planifique se torne utópica. Dicho de otra forma: la imposibilidad por parte de los legisladores de obtener la información requerida para, siquiera intentar, imitar un orden espontáneo hará pronto inútil la labor de satisfacer la multiplicidad de objetivos que constantemente surgen en una ciudad. Más allá de ello, colisionará con ellos.

El territorio tiene un orden propio fruto de la interacción de los ciudadanos. No hay que ordenarlo porque tiene vida propia y es dinámico, hay que crear las normas que protejan los derechos de los ciudadanos y que por lo tanto permitan que se forme ese orden espontáneo que le es propio y que se basa en permitir la libre actividad empresarial a través del respeto del derecho de propiedad. La planificación es un instrumento puesto al servicio de un fin de forma que se pueda alcanzar con mayores garantías de costo, tiempo y calidad. Y los fines forman parte de la acción humana tanto en su vertiente individual como en la organizada por distintos individuos que asocian entre si (empresas). La extrapolación de esta instrumentación a la ciudad es un grave error conceptual. La ciudad no es un agente empresarial que tenga objetivo ni fin propio alguno por lo que no tiene nada que planificar que no sea la libertad de las personas. Si la ciudad tiene algún objetivo este es el de facilitar que los ciudadanos puedan desarrollar su función empresarial ${ }^{14}$ y por lo tanto luchar por que consigan sus objetivos. Para ello la ciudad tendrá que garantizar la libre convivencia entre todos los ciudadanos que pasa por tener una legislación que permita la adecuada resolución de los conflictos materializados en externalidades negativas. La zonificación moderna intenta solucionar estos conflictos «ordenando el territorio». Como dice Lorenzo Infantino «el estado es solo un remedio imperfecto mediante el cual tratamos de defendernos

3 Huerta de Soto (2010)

14 Nótese que hablamos de la función empresarial en el sentido misiano del término. En el que se asimila a la propia acción humana y que por lo tanto comprende aquellos actos propios del ser humano, incluyendo el deseo de protección del entorno, de conservación inmuebles de especial valor arquitectónico, de solidaridad, etc. 
de las imperfecciones humanas. Por eso no es necesario recurrir para todo a la intervención del legislador, porque este, al ser imperfecto, esta sujeto a multiplicar sus propios errores». ${ }^{15}$ En un afán desmedido por terminar con los conflictos de convivencia la zonificación planificada dificulta esta convivencia eliminando con ella todas las bondades que se derivan de su ejercicio voluntario.

Por lo tanto toda planificación debería limitarse a diseñar contados objetivos estratégicos que libre y voluntariamente quieran asumir los ciudadanos. Ni siquiera en la hipótesis de grandes ciudades de propiedad privada una planificación central es aconsejable. A partir de determinadas dimensiones la ciudad empresarial, aunque sea de un único propietario, debe permitir la libre competencia interna que permita la creación de órdenes complejos que garanticen la flexibilidad para alcanzar los fines vitales de los ciudadanos y la máxima eficiencia para lograr la prosperidad.

El derecho urbanístico español, heredero de posturas positivistas, interviene de esta forma invasiva en la vida de los ciudadanos creando grandes distorsiones que limitan nuestros derechos más primarios como son los derechos a la propiedad y a la concertación libre de contratos dentro de una regulación natural del territorio. Se trata de un derecho estructurado para lograr un orden esencialmente planificado y que responde a una concepción socialista de la organización de la sociedad. Frente a esta hiper estructura legislativa, se aboga por un derecho urbanístico fruto del derecho consuetudinario y fundamentado en la protección de los derechos que nos son propios como son el derecho a la vida, a la propiedad y a los contratos.

\section{ESPONTANEIDAD Y ORDEN EVOLUTIVO EN EL URBANISMO}

Sabemos, por Ludwig Von Mises ${ }^{16}$ que si echamos una vista al pasado debemos hacerlo con cautela. La lectura de la historia debe

\footnotetext{
15 Infantino (2000).

16 Von Mises (2010).
} 
realizarse siempre a través del prisma de una teoría correcta que nos permita vislumbrar los juicios de valor que en cada momento sirvieron de resorte para que se produjese la acción humana y empresarial que impulsó cada una de las actuaciones urbanísticas. El resultado final es producto de las múltiples acciones empresariales y actos de voluntad de las diferentes generaciones que poblaron la ciudad. Su materialización en una trama urbana que nos viene legada, oculta todas las interacciones humanas que la hicieron posible. Por lo tanto, un intento de lectura del urbanismo desde nuestra óptica, sin la realización del acto simpático, en su sentido más smithiano, ${ }^{17}$ y praxeológico de ponernos en el lugar de los ciudadanos que edificaron la ciudad nos abocaría a una interpretación equivocada del urbanismo y de su desarrollo.

Hayek estudia el concepto de orden y diferencia entre el orden creado y el orden espontáneo. Para Hayek los ordenes espontáneos «facilitan la consecución del mayor número posible de objetivos individuales». Hay que decir que este es una error habitual de la extensión que a la palabra planificación se le ha dado hoy en día derivado del concepto de planificación socialista. En línea con lo indicado por Hayek, al igual que los órdenes espontáneos «facilitan la consecución del mayor número posible de objetivos individuales», ${ }^{18}$ los ordenes creados lo son en función de un limitado número de fines que quiere lograr el planificador. Esto por supuesto, sin perjuicio de que los órdenes espontáneos que subyacen a este orden creado no intenten abrirse paso. La consecuencia nefasta de esto es que fabricar órdenes con el objetivo de lograr ciertas finalidades, entra en conflicto con las finalidades que otros individuos pudieran tener y con los órdenes espontáneos que de ellas puedan derivarse. Esto es especialmente visible en la ciudad. La "ordenación del territorio» por parte del planificador se realiza con la finalidad de lograr una serie de objetivos, de inevitable corto alcance debido a las limitaciones intelectuales que como ser humano tiene el planificador. Estos objetivos no solo tienen una eficiencia muy limitada en el orden social urbano sino que además entran en conflicto con la

\footnotetext{
17 Infantino (2000), p. 52

18 Martínez Meseguer (2009).
} 
inmensa diversidad de fines de los distintos agentes que actúan en la ciudad.

En su doble afán, primero por controlar lo que sucede y lo que pueda suceder en la sociedad y segundo por pensar que la planificación es más efectiva que la interacción espontánea de los agentes, el planificador bloquea torpemente la riqueza que produce la interacción de las personas. De este modo puede acabar, no solo con la «eficiencia dinámica» ${ }^{19}$ de la interacción de las personas sino con el conocimiento evolutivo que esa misma interacción va depositando en acervo cultural de esa sociedad.

Por ello es perentorio el desarrollo de un urbanismo que no pretenda en ningún caso planificar de forma general la ciudad.

VI

\section{EL URBANISMO ACTUAL COMO MANDATO}

El urbanismo español es una creación centralizada donde la iniciativa empresarial tiene un margen de actuación realmente ínfimo. A esto se le añaden males periféricos que responden a los mismos patrones de la ley y el mandato de los que habla Hayek. $Y$ es que el urbanismo, como el resto del ordenamiento jurídico maneja una gran mayoría de mandatos. Y esto es así porque diseña centralizadamente el urbanismo y ha renegado de la propiedad, de la libre coordinación entre las personas, de las tradiciones y de las costumbres que son la base de un urbanismo creativo desde sus orígenes. La creación tanto artística como funcional nunca lo es ex nihilo. En contra de lo que pudiera parece la creación pura es una ficción imposible de pensar. Es por lo tanto necesario tanto para la creación tecnológica, como para la empresarial la transmisión de los conocimientos y costumbres heredados. En el caso concreto del urbanismo son vitales los conocimientos históricos que sólo pueden transmitirse a través de la universidad, que actualmente reniega de los mismos en favor de una falsa

\footnotetext{
19 Huerta de Soto (2004).
} 
innovación. Desafortunadamente hace ya mucho tiempo que la universidad no ha sabido conciliar un saber que debería haber acumulado con los nuevos conocimientos que emergían. Vaciada de su carácter humanista es incapaz de transmitir las costumbres de una sociedad.

Así mismo son vitales las costumbres del lugar que se transmiten de generación en generación a través de los distintos oficios (carpinteros, albañiles, etc.) y que posibilitan conocer técnicas y lugares (evacuación de aguas, trazado de senderos, barrancos, etc.) de vital importancia para concebir el urbanismo y para la innovación.

\section{VII \\ EFECTO DE LAS DIFERENTES LEYES URBANÍSTICAS EN LA EFICIENCIA DINÁMICA DE LA CIUDAD}

Como ya hemos indicado, el urbanismo ha sufrido de una forma especialmente contundente la concepción estática de la ley, reduciendo al mínimo el margen de actuación dinámica del ciudadano y del empresario. Pero ¿de que manera se ha materializado esta fuerte intervención gubernativa? Tomando como ejemplo una comunidad autónoma como la Canaria podemos ver hasta cuatro niveles de legislación urbanística de carácter netamente intervencionista se solapan en España creando una red burocrática en la que es difícil moverse. Legislación estatal (Ley del suelo) ${ }^{20}$, legislación autonómica (Ley del Territorio de Canarias) ${ }^{21}$, legislación insular (Planes insulares de ordenación del territorio) ${ }^{22}$ y legislación local (planes generales de ordenación y normas subsidiarias), ayudadas y apuntaladas por normas de detalle (planes de modernización, medio ambientales, estudios de detalle, etc.),

20 Real Decreto Legislativo 2/2008, de 20 de junio, por el que se aprueba el Texto Refundido de la Ley de Suelo.

${ }^{21}$ Decreto Legislativo $1 / 2000$, de 8 de mayo, por el que se aprueba el Texto Refundido de las Leyes de Ordenación del Territorio de Canarias y de Espacios Naturales de Canarias.

22 Planes insulares de cada una de las islas. 
sectoriales (Ley de Costas, Puertos, etc.) y aquellas de carácter técnico que podríamos llamar de «calidad» que también se solapan a distintos niveles: a nivel estatal el Código Técnico de Edificación, ${ }^{23}$ a nivel autonómico normativas de habitabilidad, ${ }^{24}$ accesibilidad, ${ }^{25}$ etc., a nivel local ordenanzas estéticas, de uso de espacios exteriores, etc.

Hay muchas formas de bloquear la función empresarial del ser humano: impuestos, trabas burocráticas, etc., que desalientan la empresa de conseguir determinado fin. En el urbanismo español podemos observar cómo se han ido bloqueando casi la totalidad de las vías que permitían la función empresarial a las que hay que añadir los obstáculos habituales de la actividad económicoempresarial.

Tal y como hemos dicho, la concreción de este bloqueo se materializa en primer lugar a través de la asignación discrecional de los distintos usos del suelo. Es en el suelo en el se desarrollan las ciudades y es solo mediante un libre uso del mismo como podrían aprovecharse sus potencialidades.

Debemos tener en cuenta la importancia que tiene el territorio en nuestra vida cotidiana y en el desarrollo de nuestras potencialidades. El suelo es el espacio físico en el que se llevan a cabo la mayoría de nuestras actividades de forma que podemos afirmar que la planificación, desarrollo, reforma y ampliación de los edificios y de los espacios de las ciudades y externos a estas tendrá una incidencia capital en las actividades que los ciudadanos puedan realizar, en su forma de realizarlas y por lo tanto en la función empresarial que les es propia y en la eficiencia dinámica.

${ }^{23}$ Real Decreto 314/2006, de 17 de marzo, por el que se aprueba el Código Técnico de la Edificación.

${ }^{24}$ Decreto 117/2006, de 1 de agosto, por el que se regulan las condiciones de habitabilidad de las viviendas y el procedimiento para la obtención de la cédula de habitabilidad.

${ }^{25}$ Ley 8/1995, de 6 de abril, de accesibilidad y supresión de barreras físicas y de la comunicación. 
VIII

\section{LEGISLACIÓN ESTATAL, AUTONÓMICA Y LOCAL. LA MARAÑA DE LEGISLACION URBANÍSTICA}

Así pues el urbanismo actual planifica el suelo y el uso que se hace de este desde los ámbitos más generales (Ley del Suelo) ${ }^{26}$ hasta los más concretos (Planes Generales de Ordenación) pasando por los intermedios, legislados por las leyes territoriales de tipo autonómico ${ }^{27}$ y por las leyes técnicas (normativa de habitabilidad, ${ }^{28}$ Código Técnico de Edificación, ${ }^{29}$ etc.). Desarrollando estas y otras leyes los legisladores han «logrado» crear una confusa maraña legislativa que no sólo producen un bloqueo administrativo e ineficiencia dinámica propios debido a su acumulación sino que han conseguido bloquear la eficiencia dinámica empresarial de los ciudadanos entre otros a través de los siguientes mecanismos:

- La expropiación de suelo privado y conversión en público en función de un justiprecio que no tiene en cuenta el valor subjetivo de la propiedad.

- El vaciado de contenido de la propiedad privada mediante la zonificación.

- La imposición de criterios técnicos y de diseño en la edificación.

- La imposición del diseño de la ciudad y del trazado de las vías de comunicación.

En contraposición a estos mecanismos de control la existencia de una red vial privada y de espacio públicos de propiedad privada permitiría un mayor aprovechamiento de este recurso

26 Real Decreto Legislativo 2/2008, de 20 de junio, por el que se aprueba el Texto Refundido de la Ley de Suelo.

27 Decreto Legislativo 1 / 2000, de 8 de mayo, por el que se aprueba el Texto Refundido de las Leyes de Ordenación del Territorio de Canarias y de Espacios Naturales de Canarias.

28 Decreto $117 / 2006$, de 1 de agosto, por el que se regulan las condiciones de habitabilidad de las viviendas y el procedimiento para la obtención de la cédula de habitabilidad.

29 Real Decreto 314/2006, de 17 de marzo, por el que se aprueba el Código Técnico de la Edificación. 
frente al mismo gestionado de forma centralizada por entes públicos. Una ciudad en la cual los servicios no estuviesen monopolizados por el estado permitiría una eficiencia, un equilibrio medioambiental, un progreso, y un impulso continuo a la investigación y desarrollo, mayores que en la ciudad actual. La llamada calificación del suelo que divide el territorio entre suelo urbano y suelo rústico genera una inflación importante de los precios contribuyendo así a la creación de «burbujas» y una distorsión en los mismos. Esta calificación así como la clasificación interna de los núcleos urbanos vacía, en gran medida, la propiedad de contenido, vulnerando así, de forma dictada, esos principios esenciales que permiten que una sociedad pueda desarrollarse en libertad. La zonificación del suelo urbano desde un órgano central genera importantes ineficiencias económicas y sociales. Lo que en principio pretendía solventar los problemas causados por externalidades negativas se ha convertido en un instrumento de ingeniería social. Por otra parte, es de gran importancia no perturbar la transmisión de los conocimientos que forman parte de la sociedad y que, en consecuencia, de una u otra forma contribuyen a la configuración de la ciudad.

\section{Los espacios públicos. Los recursos infrautilizados}

En el interior de la ciudad, y con la excusa de «dotar de espacios públicos» al territorio, el legislador, crea calles, parques y plazas en las que la empresarialidad se anula al impedir su uso privativo. La utilidad de los espacios públicos se reduce casi exclusivamente al tránsito y a la observación. En estos lugares se podría generar además una cantidad ingente de recursos: espacios para conciertos, manifestaciones artísticas, zonas comerciales, zonas deportivas, infraestructuras eléctricas, etc. Obteniendo riqueza económica y cultural para los propietarios de las mismas y para sus usuarios y potenciando la convivencia e interacción entre sus habitantes.

Las calles, plazas y playas de la ciudad son por lo general de titularidad pública. Para ser más exactos son terrenos de titularidad privada que deben costearse, ejecutarse y posteriormente 
cederse a la administración pública sin contraprestación alguna. Además el trazado viario aparece prediseñado en los planes de ordenación y en ellos ya figuran secciones tipo con las dimensiones de las aceras, calzada, etc. Las infraestructuras que alojan bajo los viales y los materiales de estos vienen determinados en un proyecto llamado de urbanización.

Esta situación de gestión pública de espacios lejos de limitarse a impedir que pueda desarrollarse una eficiencia dinámica, produce una gran ineficiencia estática. Esto es debido a que a la riqueza que se deja de producir debe sumarse una ineficaz asignación de los recursos centralmente planificados cuando el que actúa es el Estado en cualquiera de sus formas. Esta ineficiencia afecta esencialmente a:

- La vertiente temporal de su utilización. Se emplean un conjunto de recursos en un momento en el que los habitantes de la zona posiblemente no los utilizarían por no necesitarlos o por tener otras prioridades de gasto. Hecho ilustrado en la obligatoriedad de urbanizar totalmente un plan parcial aunque nadie viva en él ni haya todavía casa alguna edificada.

- La vertiente espacial. Es decir, el lugar en el que se ubica el recurso: colocación de unas pistas deportivas en un espacio ventoso porque ahí es donde dice el planeamiento que debe colocarse.

- El coste de los recursos: colocación de un pavimento de un determinado precio cuando los vecinos, conociendo su disponibilidad económica, hubiesen colocado otro de menor coste con similares características funcionales.

- La calidad de los recursos: colocación de un mobiliario urbano con una calidad superior a la requerida por los vecinos.

Como hemos dicho estos espacios públicos, planificados desde la administración que establece dimensiones y diseños de aceras, rampas, aparcamientos, etc., deben:

- Ser pagados, directamente, por el ciudadano. ${ }^{30}$

30 Decreto Legislativo 1/2000, de 8 de mayo, por el que se aprueba el Texto Refundido de las Leyes de Ordenación del Territorio de Canarias y de Espacios Naturales 
- Ser cedidos gratuitamente a la administración local correspondiente.

- Ser utilizados por la administración sin la posibilidad de obtener la información necesaria para una buena asignación.

Como el planeamiento urbanístico está enfocado al «bien común», y debe mostrar esa cara bondadosa de la que hace gala, en su ejecución enmascara a veces obligaciones como derechos. Como cuando indica que entre los derechos del propietario del suelo urbano consolidado está el «completar la urbanización de los terrenos para que las parcelas edificables adquieran la condición de solares», ${ }^{31}$ condición sin la cual no pueden edificar su terreno. Que es algo así como decir que uno tiene derecho a pagar sus impuestos. Todo ello produce una serie de ineficiencias dinámicas de las que enumero algunas a continuación:

Se produce Ineficiencia dinámica:

- A la hora de determinar las dimensiones que los propietarios consideren optimas para el acceso a sus propiedades y para la circulación entre las mismas ya que las dimensiones de las calles ya vienen preestablecidas en los Planes Generales sin que los propietarios puedan optimizarlas.

- En el aprovechamiento de los espacios públicos como recursos susceptibles de explotación económica.

- Al impedir la búsqueda de soluciones creativas que permitan mejoras en el transporte peatonal y rodado de la ciudad.

de Canarias. Artículo 73.1: «3. Los propietarios de suelo urbano consolidado tendrán los siguientes deberes:

b) Costear y, en su caso, ejecutar la urbanización de los terrenos para que adquieran la condición de solares.»

31 Decreto Legislativo $1 / 2000$, de 8 de mayo, por el que se aprueba el Texto Refundido de las Leyes de Ordenación del Territorio de Canarias y de Espacios Naturales de Canarias. Artículo 73.1: «1. Los propietarios de suelo urbano consolidado tendrán, previo cumplimiento de los deberes legales exigibles, los siguientes derechos:

a) Derecho a completar la urbanización de los terrenos para que las parcelas edificables adquieran la condición de solares.» 
- Al impedir la innovación en diseño de viales, materiales empleados para su ejecución (tipos de asfaltos, etc.), etc.

- En los costes de los materiales y soluciones constructivas de los espacios públicos. Quizá los vecinos de una calle, conociendo la limitación de sus recursos económicos o simplemente queriendo buscar una optimización de los mismos o debido a preferencias subjetivas hubiesen querido colocar un pavimento de las mismas características funcionales pero de un menor coste económico (empleo de piedra artificial en lugar de natural por ejemplo).

- A la hora de asignar recursos. En esa misma calle los vecinos están en mejor disposición que la administración de saber por ejemplo el número bancos que quieren para sentarse y el número de papeleras para mantener la calle en buenas condiciones de higiene y limpieza.

- A la hora de asignar las calidades de los recursos.

- En la aplicación temporal de los recursos: sustitución de aceras cuando no hacen falta o cuando los propietarios estiman que deben emplear ese dinero en otra actividad que subjetivamente estiman más necesaria.

- A la hora de emplear recursos humanos: Los arquitectos, ingenieros o diseñadores en lugar de realizar proyectos por requerimiento burocrático para la obtención de permisos de obra para la ejecución de viales como ocurre actualmente se dedicarían al estudio de diseños más eficientes y a la búsqueda de nuevas soluciones constructivas para la ejecución de aceras, evacuación de residuos sólidos, telecomunicaciones, etc.

Tal y como indica el profesor Huerta se Soto en referencia a la planificación socialista: «el órgano director se verá incapacitado para efectuar cálculo económico alguno en el sentido de que, con independencia de cuáles sean sus fines no podrá saber si los costes en los que incurre a la hora de perseguir dichos fines tienen para el propio órgano director un valor superior al valor que él mismo atribuye subjetivamente a los fines perseguidos. El coste no es sino el valor subjetivo que el actor atribuye a aquello a lo que renuncia al actuar persiguiendo un determinado 
fin».32 Recientemente fueron muy criticados los planes del antiguo gobierno socialista (llamados Planes E) que pretendían aumentar la inversión pública en infraestructuras urbanas con la finalidad de incrementar la actividad económica y disminuir el paro. Esta política de aumento del gasto público adolece de un desconocimiento importante del funcionamiento de la función empresarial del ser humano. En este caso nos interesa destacar la visión subjetiva de la inversión y su consecuente coste de oportunidad. Si la inversión en arreglos de cualquiera de las calles del país dependiera de los recursos de los vecinos que viven en ella es fácil adivinar que su asignación sería muy distinta. Quizá, con una economía doméstica depauperada los vecinos hubiesen optado por dejar las obras de la modernización de la vía pública para otro momento en favor de pagar deudas o arreglar elementos vitales de la vivienda. O quizá hubiesen optado en otro lugar por arreglar la calle con materiales más baratos. O, en casos extremos, sí hubiesen emprendido las obras. Lo que se puede apreciar es que la casuística sería enorme en función de las necesidades subjetivas de los habitantes del lugar. Y el uso de los recursos nunca podrá tener una asignación tan específica y tan acertada como cuando es realizada por los propietarios. Es cierto que apostar por la utilización de recursos propios trae consigo una serie de inconvenientes. Estos son inerradicables y propios de nuestra naturaleza pero, ejercidos en libertad, permiten el desarrollo cívico y moral de una sociedad.

Cuando un organismo público quiere, pongamos por caso, sustituir las farolas de un barrio de la ciudad, dispone de precios que le permiten conocer ciertas características de los materiales a emplear. El problema al que asistimos es que cuando la administración invierte en obras urbanas, carece del resto de la información necesaria para hacer el cálculo económico. Se ve con ello imposibilitada para averiguar información esencial como es la utilidad real de la inversión o el coste de oportunidad. Podríamos decir que el gobierno puede hacer un cálculo económico que contemple los ingresos y gastos de su propia contabilidad pero

\footnotetext{
32 Huerta de Soto (2010), p. 103.
} 
este cálculo no tiene en cuenta, ni puede hacerlo, las necesidades particulares de cada ciudadano que finalmente es el que sufraga las obras. Por lo tanto, la esencia del cálculo económico que es saber si se satisfacen las necesidades subjetivas de cada individuo con un ratio deseado coste-beneficio, se diluye a través de los distintos intermediarios que componen la administración pública.

La gestión centralizada es a menudo incapaz de descubrir soluciones que serían evidentes desde una gestión privada. Lo hace torpemente al simular esta situación en casos extremos. En los últimos años se ha abierto el debate sobre el pago por circular por el centro de las ciudades o el pago por los aparcamientos en superficie. Lo que sería obvio desde una situación de manejo de derechos de propiedad no lo esta tanto al manejar suelo público. Y no es de extrañar dada la imposibilidad de realizar el cálculo económico. Tal y como indica Pascal Salin ${ }^{33}$ «el derecho a utilizar un recurso escaso no puede ser absoluto y sin límites». «Los automovilistas modificarían sus decisiones si tuvieran que hacer frente a su coste efectivo».» Esto permitiría "que cada uno compare el coste de circulación con la ventaja que obtiene» y contribuiría a alentar la expansión de actividades en otros lugares. Y en ese orden de cosas el pago por el transito en lugares altamente solicitados o por el aparcamiento es, en una ciudad de propietarios, un mecanismo natural cuyas consecuencias son la racionalización de los recursos existentes y la explotación de otros más baratos, es decir menos solicitados (calles y aparcamientos del extra radio) con la inmediata consecuencia del desarrollo de otros centros neurálgicos en la ciudad.

\section{a) La privatización de los espacios públicos}

¿Qué ocurriría si se privatizasen estructuras viarias como las calles de una ciudad? Ya hemos dicho que es aventurado realizar hipótesis sobre las soluciones de futuro en el funcionamiento de

\footnotetext{
${ }^{33}$ Salin (2000 [2008]), p. 304.
} 
una ciudad libre. La creatividad humana hace impredecible saber que cosas se descubrirán. A pesar de ello sabemos que privatizar las infraestructuras viarias permitiría el surgimiento de empresas especializadas en su diseño y en el asesoramiento de su forma de ejecución, creación de viales de múltiples tipologías y soluciones funcionales que mejorasen la movilidad rodada o peatonal. El urbanista comenzaría su especialización en las diferentes actividades de diseño y planificación que requiere la ciudad y pasaría de su situación de «fatal arrogancia» del gran planificador de despacho actual, que se concreta en los Planes Generales ajenos a la realidad individual y a la dinámica de la ciudad, al asesor, que a pie de calle, diseñaría sistemas de comunicación a dúo con la creatividad y coordinación empresarial. Las soluciones que aportaría no las podemos ni imaginar desde lo estático como diría Israel Kirzner dejando patente lo inabarcable de la creatividad humana. Sabemos que los espacios públicos, en tanto que públicos, están vetados a la función empresarial (concesiones administrativas al margen).

Podríamos pensar que en el ámbito de lo privado, o sea fuera de la red pública de calles, parques y jardines, uno ya puede desarrollar su iniciativa conforme a la visión creativa y coordinadora que le es propia. Nada más lejos de la realidad. No quedan ahí los bloqueos a la creatividad y a la coordinación empresarial. La propiedad privada perdió su protección desde la propia Constitución. ${ }^{34}$ Definir a España como un «estado social» abrió la veda para que en el ámbito del urbanismo cualquier usurpación de la propiedad privada estuviese amparada por un supuesto «bien común» que la legitimaba y pudiese realizarse discrecionalmente. Así, en el caso de que uno tuviera ya edificado su terreno dejarlo «fuera de ordenación» (y por lo tanto bloquear cualquier posibilidad de actuación $)^{35}$ es tan fácil como asignar

34 Constitución Española. Artículo 1: «España se constituye en un Estado social y democrático de Derecho, que propugna como valores superiores de su ordenamiento jurídico la libertad, la justicia, la igualdad y el pluralismo político.»

35 Decreto Legislativo 1/2000, de 8 de mayo, por el que se aprueba el Texto Refundido de las Leyes de Ordenación del Territorio de Canarias y de Espacios Naturales de Canarias. Artículo 44: «...se aplicarán a las instalaciones, construcciones y edificaciones en situación de fuera de ordenación las siguientes reglas: 
otro uso, modificar cualquiera de los parámetros de la parcela en la que se ubica o ampliar la calle que le da acceso. Que tu propiedad sea «galardonada» con un BIC (Bien de Interés Cultural) por sus excepcionales características es otra losa que también pueden depositar sobre tu propiedad sin indemnización previa. Por si fuera poco y si dispusieses de una parcela en la que por casualidad mal pudieras desarrollar parte de lo que deseas, dispones de un límite máximo para solicitar la licencia de dos años. ${ }^{36}$ Evidenciando que la visión dinámica no existe en el planeamiento ni en su más elemental manifestación empresarial, al considerar que es irrelevante la decisión del momento en que debe realizarse determinada inversión y obligándote a llevarla a cabo como máximo en dos años bajo amenaza de expropiación. ${ }^{37}$ Esto crea un mal por si mismo a los legítimos propietarios pero su combinación con un sistema legislativo de corte positivo crea una enorme inseguridad jurídica dada la potestad del legislador, o sea del gobernante, de modificar discrecionalmente la normativa urbanística vigente. Tal y como lo expone Bruno Leoni al criticar a quienes defiende una ley por el mero hecho de estar escrita, «la certeza de la ley en sentido de una fórmula escrita, se refiere a

1. Con carácter general sólo podrán realizarse las obras de reparación y conservación que exija la estricta conservación de la habitabilidad o la utilización conforme al destino establecido. Salvo las autorizadas con carácter excepcional conforme a la regla siguiente, cualesquiera otras obras serán ilegales y nunca podrán dar lugar a incremento del valor de las expropiaciones.

2. Excepcionalmente podrán autorizarse obras parciales y circunstanciales de consolidación cuando no estuviera prevista la expropiación o demolición, según proceda, en un plazo de cinco años, a partir de la fecha en que se pretenda realizarlas. Tampoco estas obras podrán dar lugar a incremento del valor de la expropiación.»

36 Decreto 183/2004 por el que se aprueba el Reglamento de Gestión y ejecución del sistema de planeamiento de Canarias. Capítulo III «Organización temporal de la gestión y la ejecución. Artículo 16: «Condiciones para establecer los plazos máximos»; e) «Para solicitar licencia de edificación en parcelas de suelo urbano consolidado: 2 años, desde la entrada en vigor del planeamiento que la legitime.»

37 Decreto 183/2004 por el que se aprueba el Reglamento de Gestión y ejecución del sistema de planeamiento de Canarias. Capítulo III «Organización temporal de la gestión y la ejecución». Artículo 17: «Incumplimiento de los plazos máximos de ejecución». 4) «El incumplimiento de los plazos máximos establecidos por el planeamiento para solicitar licencia de edificación...tendrá los efectos que se deriven de la declaración del incumplimiento y de la edificación forzosa de la edificación por sustitución del propietario mediante concurso público convocado al efecto». 
un estado de cosas inevitablemente condicionado por la posibilidad de que la ley actual puede ser reemplazada en cualquier momento por otra. Cuanto más intenso y acelerado sea el proceso legislativo (caso español) ${ }^{38}$, más incierto resultará el problema de la duración de la legislación presente». ${ }^{39}$ Esta nefasta consecuencia en la seguridad jurídica es especialmente dañina en el caso urbanístico ya que en otros ámbitos jurídicos la irretroactividad de las leyes aporta cierta seguridad. Sin embargo en el ámbito urbanístico uno puede adquirir un terreno urbano creyendo que uno está adquiriendo un derecho inatacable a edificar pero en pocos meses esa norma puede ser modificada o derogada sin necesidad de comunicación personal alguna. $\mathrm{O}$ en caso de tener ya edificado el solar dejar «fuera de ordenación» ${ }^{40}$ el inmueble con un cambio legislativo mínimo.

La situación por lo tanto del planeamiento tiene diferentes facetas en lo que al bloqueo de la eficiencia dinámica del ciudadano se refiere. Una primera, altamente invalidante, que es la de destinar espacios a uso público. Otra segunda que es la de vaciar de contenido la propiedad privada o limitarla a márgenes muy reducidos sin posibilidad de movimiento creativo ni coordinador que es la calificación del suelo o zonificación. Una tercera que es la de limitación de tiempos para la ejecución que llega incluso a autorizar la «sustitución del propietario» ${ }^{41}$ cuando indica que

38 El paréntesis es mío.

39 Leoni (1961[1995]), p. 99.

40 Decreto Legislativo 1/2000, de 8 de mayo, por el que se aprueba el Texto Refundido de las Leyes de Ordenación del Territorio de Canarias y de Espacios Naturales de Canarias. Artículo 44: «... se aplicarán a las instalaciones, construcciones y edificaciones en situación de fuera de ordenación las siguientes reglas:

1. Con carácter general sólo podrán realizarse las obras de reparación y conservación que exija la estricta conservación de la habitabilidad o la utilización conforme al destino establecido. Salvo las autorizadas con carácter excepcional conforme a la regla siguiente, cualesquiera otras obras serán ilegales y nunca podrán dar lugar a incremento del valor de las expropiaciones.

2. Excepcionalmente podrán autorizarse obras parciales y circunstanciales de consolidación cuando no estuviera prevista la expropiación o demolición, según proceda, en un plazo de cinco años, a partir de la fecha en que se pretenda realizarlas. Tampoco estas obras podrán dar lugar a incremento del valor de la expropiación.»

${ }^{41}$ Decreto 183/2004 por el que se aprueba el Reglamento de Gestión y ejecución del sistema de planeamiento de Canarias. Capítulo III «Organización temporal de la 
«el incumplimiento de los plazos máximos establecidos por el planeamiento para solicitar licencia de edificación...tendrá los efectos que se deriven de la declaración del incumplimiento y de la edificación forzosa de la edificación por sustitución del propietario mediante concurso público convocado al efecto.»

\section{La clasificación del suelo.}

\section{El vaciado de contenido de la propiedad privada}

El vaciado de contenido de la propiedad privada se produce por lo tanto a través de:

1. La Clasificación del suelo: El miedo a una edificación de todo el territorio impulsó una clasificación del suelo en:

- Suelo Urbano.

- Suelo Urbanizable.

- Suelo Rústico. ${ }^{42}$

2. La Calificación del suelo: La también llamada zonificación que pretende separar usos incompatibles entre si, razón por la cual te indica qué tipo de actividad puede desarrollarse en cada tipo de suelo. Además regula el aspecto físico de las edificaciones al regular parámetros como: edificabilidad, ${ }^{43}$ ocupación, ${ }^{44}$ número de plantas, altura, etc.

3. La Gestión Urbanística ${ }^{45}$ : Establecimientos de ejecución, cesiones obligatorias, etc.

gestión y la ejecución». Artículo 17: «Incumplimiento de los plazos máximos de ejecución».4) «El incumplimiento de los plazos máximos establecidos por el planeamiento para solicitar licencia de edificación... tendrá los efectos que se deriven de la declaración del incumplimiento y de la edificación forzosa de la edificación por sustitución del propietario mediante concurso público convocado al efecto.»

42 O suelo no urbanizable.

43 Número de metros cuadrados que pueden edificarse en relación con los metros cuadrados de solar de que disponemos.

${ }^{44}$ Número de metros cuadrados que pueden ocuparse en relación con los metros cuadrados de solar de que disponemos.

45 Decreto 183/2004, 21 diciembre, por el que se aprueba el Reglamento de gestión y ejecución del sistema de planeamiento de Canarias. 
Tanto la clasificación como la calificación producen una serie de ineficiencias dinámicas de las que destacamos las siguientes:

- En el precio del suelo. El hecho de que solo se pueda edificar en Suelo Urbano restringe absolutamente el suelo disponible. Se produce una situación de oligopolio ya que el suelo está en manos de unos pocos propietarios. Nos encontramos con especulación en situación de fuerza por imposibilidad de entrada de competidores.

- En los tiempos y costes de licencias urbanísticas. La regulación de las condiciones de construcción y de desarrollo de actividades conlleva un control a priori que repercute muy negativamente en la eficiencia de cualquier iniciativa empresarial.

- En la convivencia de los ciudadanos ya que las costumbres quedan anuladas por la legislación.

- En la eficiencia energética y estética por abandono de las antiguas costumbres constructivas, arquitectónicas y urbanísticas de una ancestral y evolutiva sabiduría en favor de nuevos diseños menos conocedores del entorno. Abandono del Patio Canario, construcción con grandes ventanales, reducción de la sección de los muros de cerramiento de fachada, abandono de las cubiertas planas como recogedoras de agua de pluviales, etc.

- En el medio ambiente rural, ya que al vaciarse de contenido el derecho de propiedad hay terrenos en los que realmente no puede hacerse nada o casi nada y por lo tanto han quedado desatendidos.

- A través de la incertidumbre ocasionada por la inseguridad jurídica producida por el marco legislativo actual. El derecho positivo y en concreto el derecho urbanístico como paradigma del positivismo jurídico crea una gran inseguridad jurídica en contra de lo que habitualmente se piensa ya que como ya advirtió Bruno Leoni uno queda siempre con la duda de los cambios que el legislador pueda dictar.

- Expropiación de suelo sin infraestructuras a precio de rústico.

- En la asignación a ciertas edificaciones de las características de Bien de Interés Cultural. Actualmente que cataloguen una edificación de tu propiedad como Bien de Interés Cultural es un problema. Dada la enorme dificultad de realizar obras de 
reparación y mejora es probable que sea su ruina y la tuya. Debido a que esta catalogación no lleva consigo una indemnización automática a precios de mercado se produce una sobreprotección del patrimonio de forma indiscriminada ya que la ausencia del mecanismo de mercado no permite saber si el coste de la protección es razonable o no.

- En la protección de espacios medio ambientales. Es un caso similar al anterior. No se produce indemnización por lo que el sistema de precios no funciona y no se puede saber si el coste de la protección es adecuado o es más conveniente su libre utilización.

En la elección de los usos. Un empresario, gracias a su talento y al conocimiento del sector puede considerar que una determinada actividad funcionaría perfectamente en un terreno de su propiedad pero el Plan General no te permite ponerla en funcionamiento porque los redactores consideraron que esa actividad no debía realizarse allí. Podría ser el caso por ejemplo del establecimiento hotelero que lleva 20 años en explotación y cuyo suelo es de nuevo regulado por el planeamiento. Se le prohíbe esta vez el uso hotelero porque considera el gobernante que los usos residencial y turístico no deben mezclarse. ${ }^{46}$ Cuando alguien quiera construir, pongamos por caso, un centro comercial en un determinado suelo se encontrará que solo podrá hacerlo si la casualidad (es decir la decisión del gobierno de turno, en este caso local y autonómico) haya decidido que así sea. Es difícil cuantificar las pérdidas económicas derivadas de la falta de eficiencia de este tipo de bloqueos pero sí podemos decir que se derivan de una superposición de leyes, normas y mandatos en general que multiplican sus efectos. Tal y como dice el profesor Huerta de Soto «el principal efecto del socialismo, tal y como lo hemos definido, es el de impedir que actúen las fuerzas coordinadoras que hacen posible la vida en sociedad» de modo que la ciudad

46 Ley 19/2003, de 14 de abril, por la que se aprueban las Directrices de Ordenación General y las Directrices de Ordenación del Turismo de Canarias. Directriz 12: «1. El planeamiento evitará el uso mixto residencial y turístico en las zonas turísticas, por los efectos de deterioro de la oferta alojativa». 
perderá su eficiencia dinámica a favor de un estéril control gubernamental.

Así pues cuando en una ciudad se realiza la planificación de sus usos a través de lo que se ha venido en llamar zonificación estamos ante un orden aparente. Un orden vulgar que no va más allá (que no puede ir más allá), de un orden aparente. Cuando equipos completos de ingenieros y arquitectos llegan a estas conclusiones de orden simplificado nos damos cuenta de las tremendas limitaciones que tiene el ser humano cuando se cree organizador de una sociedad. Sin embargo las capacidades organizativas se multiplicarían solo con el hecho de ser consciente de que debe permitirse la interacción entre ciudadanos.

«Al impedirse en mayor o menor grado el ejercicio de la función empresarial, se imposibilita el que ésta descubra las situaciones de desajuste que se dan en la sociedad. Al impedirse coactivamente que los actores se aprovechen de las oportunidades de ganancia que siempre genera todo desajuste». ${ }^{47}$ Por otro lado, tampoco cabe concebir que el órgano director encargado de ejercer la coacción institucional sea capaz mediante sus órdenes y mandatos de coordinar el comportamiento social. «Esta frustración de planes o descoordinación generalizada afecta a la esencia misma de la vida social y se manifestará tanto intratemporal como intertemporalmente.» ${ }^{48}$

A continuación se expone una definición de orden que se ajusta más a una concepción universal del orden. «Para Hayek «orden» es todo proceso en el cual una multitud de elementos de diversa especie se relacionan entre sí de tal manera que el conocimiento de una parte del conjunto permite formular acerca del conjunto expectativas adecuadas que son ciertas. De acuerdo con esta definición, se hace evidente el papel del socialismo como generador de desorden social». Lo que aparentemente era orden resulta ser desorden. El socialismo por lo tanto, a pesar de las apariencias, desordena.

\footnotetext{
${ }^{47}$ Huerta de Soto (2010), p. 111

48 Huerta de Soto (2010), p. 111.
} 


\section{La gestión urbanística}

Decíamos anteriormente que creada una ley de mandato, se crean unas distorsiones que pretenden arreglarse con nuevas leyes. A estas segundas pertenecen las que se engloban en lo que se ha venido en llamar Gestión Urbanística a través de los Instrumentos de Planeamiento urbanístico. Estos esconden, bajo procedimientos aparentemente benévolos, un nuevo sistema de despojo del ciudadano y de sobrecoste de los recursos. Veamos algunos de estos instrumentos de ordenación:

\section{a) Unidades de actuación}

El procedimiento legislativo diseñado para el desarrollo del suelo urbano que todavía está sin urbanizar, es decir que carece, entre otros, de edificaciones, viales e infraestructuras, es el de las llamadas Unidades de Actuación. Este sistema posibilita que, por medio de una reparcelación de los terrenos, ningún propietario de la bolsa de terreno a urbanizar se vea perjudicado ni beneficiado más que otro en el reparto de cargas y beneficios. Se realiza así un reparto proporcional. Sin embargo bajo este «ingenioso» sistema se esconde una más de las ineficiencias y de los sobrecostes del derecho urbanístico actual. Cuando alguno de los legítimos propietarios de los terrenos decide edificar (o mejor dicho, cuando está obligado a hacerlo) ${ }^{49}$, este debe someterse a los siguientes mandatos: 1. ${ }^{\circ}$ Ceder, gratuitamente, ${ }^{50}$ los terrenos previstos para los viales públicos que estén contemplados en esta unidad de actuación por el Plan General de Ordenación. Viéndose obligado a desprenderse de un recurso de gran utilidad a favor de la administración que no paga nada por ello.

49 Real Decreto 3288/1978, de 25 de agosto, por el que se aprueba el Reglamento de Gestión Urbanística para el desarrollo y aplicación de la Ley sobre régimen del Suelo y Ordenación Urbana.

50 Art. 46 Real Decreto 3288/1978, de 25 de agosto, por el que se aprueba el Reglamento de Gestión Urbanística para el desarrollo y aplicación de la Ley sobre régimen del Suelo y Ordenación Urbana. 
2. ${ }^{\circ}$ Costear ${ }^{51}$ la ejecución de los viales, previamente a la citada cesión, y las correspondientes infraestructuras (saneamiento, alumbrado, electricidad, agua). 3. Ceder los espacios para zonas verdes y ejecutar las mismas. $4 .{ }^{\circ}$ Finalmente, después de estas cesiones gratuitas de terrenos e infraestructura quedará una superficie neta de la cual deberán ceder un $15 \%$ de su aprovechamiento. ${ }^{52}$

Toda esta cascada de costes agregados derivados de cesiones y de construcción de infraestructuras dificulta extremadamente, por su rigidez, cualquier innovación tecnológica que permita una mayor eficiencia y obliga a alcanzar en la ejecución de las edificaciones unos costes que superarían para cualquier bien un precio adecuado para el. Que la vivienda pueda encuadrarse en lo que Abraham Maslow llamaría una necesidad básica, la realidad oligopólica del suelo urbano y la inexistencia de bienes sustitutivos han permitido que hayamos soportado el pago de todos estos sobrecostes. No obstante el daño al progreso y a la prosperidad de los ciudadanos es incuestionable.

\section{b) Los planes parciales}

En semejante situación nos encontramos cuando hablamos de los Planes Parciales. Estos permiten desarrollar el llamado Suelo Urbanizable Programado. El procedimiento es similar y juega también en él un papel importante el llamado «aprovechamiento urbanístico» que es una unidad de medida que sustituye los habituales metros cuadrados al incorporar características del suelo tales como el uso permitido, la situación dentro de la parcela, etc. Este invento nace en ese afán de que haya una justicia en el reparto. Parafraseando de nuevo a Bastiat: «observad que lo que yo les niego no es el derecho a inventar combinaciones sociales, a difundirlas, aconsejarlas y experimentarlas en ellos mismos, a su

51 Art. 59 Real Decreto 3288/1978, de 25 de agosto, por el que se aprueba el Reglamento de Gestión Urbanística para el desarrollo y aplicación de la Ley sobre régimen del Suelo y Ordenación Urbana.

52 Se hará referencia al aprovechamiento en el apartado «Los planes parciales y el aprovechamiento». 
costa y riesgo, sino el derecho a imponérnoslas por medio de la ley, es decir de la coacción y de los impuestos.» ${ }^{53}$

\section{Imposicion de criterios técnicos y de diseño}

Normativas como el Código Técnico de Edificación o normativas reguladoras de las condiciones de habitabilidad intervienen directamente en los diseños tanto constructivos como funcionales de las viviendas, edificaciones y soluciones urbanas en general produciendo importantes situaciones de bloqueo de la eficiencia dinámica. La casuística es muy amplia. A título de ejemplo podemos indicar que se produce ineficiencia dinámica en:

- Imposibilitar la utilización determinados materiales.

- Impedir el descubrimiento de nuevas soluciones más eficaces y eficientes. Es decir bloqueando la innovación al imponer las soluciones a problemas determinados.

- En la obligatoriedad de cumplir con unas dimensiones mínimas en viviendas que en caso contrario no permiten dotarlas de ciertos espacios o llegan a impedir la construcción de la vivienda. Todo ello a pesar de que se trate de una vivienda propia y aceptes voluntariamente tener un aseo inferior al indicado en normativa porque solo dispones de ese espacio.

- En los costes. Ya que obliga a implantar una serie de exigencias que el usuario final puede no desear.

- Entorpecer la competencia al impedir que las empresas puedan diferenciarse aportando una calidad que las otras no dan.

- En la ejecución de viviendas de calidad inferior. Se produce un mecanismo similar al de la elevación del sueldo mínimo interprofesional ya que los grandes requerimientos técnicos elevan los costes de las viviendas y las personas más desfavorecidas no pueden acceder a ellas.

- En el caso concreto de las normas de accesibilidad se intenta legislar aquello que forma parte de la sensibilidad humana y

53 Bastiat (1850 [2009]), p. 226. 
por tanto social hacia los más desfavorecidos, en este caso por sus dificultades para desplazarse. Imponiendo la solidaridad una vez más, deshumanizando la sociedad que debería llegar a esas soluciones por una consciencia de lo que debe hacerse y no por una imposición legislativa.

Y es que imponer la calidad entra dentro del campo de lo absurdo cuando el comprador es libre para elegir aquello que desea. La calidad es fruto de la competencia y de la riqueza de una sociedad. Una sociedad rica podrá aspirar a estándares de calidad mayores siempre y cuando quieran ser elegidos libremente por cada comprador después de un cálculo subjetivo de coste-beneficio. Pero en ningún caso deben ser impuestas desde la administración ya que minan el derecho a rechazar calidades no prioritarias para el comprador, impiden que los productores que quieren ofrecer mayor calidad frente a los demás se diferencien de estos y por la misma razón no permiten ofertar calidades inferiores a los compradores con menos recursos o con otras prioridades. Desde esta perspectiva socialista de la calidad «Como se ve, los hombres, no son más que viles materiales. No son ellos los que quieren el bien, pues son incapaces de quererlo; es el legislador quien lo quiere» ${ }^{54}$ «Cuando la ley impone un modo de trabajar (aquí diríamos de construir) actúa sobre los hombres no de forma negativa sino positiva. Los individuos no tienen ya que consultarse, que comparar, que prever. La ley lo hace por ellos. La inteligencia se les convierte en un mueble inútil; dejan de ser hombres; pierden su personalidad, su libertad, su propiedad.» 55

\section{Imposición del diseño de la ciudad y del trazado de las vias de comunicación}

Se produce ineficiencia dinámica en el bienestar humano que pasa de vivir en una ciudad creada por sus habitantes de una forma evolutiva a una ciudad prefabricada, ortogonal y repetitiva fruto del

\footnotetext{
${ }^{54}$ Bastiat (1850 [2009]), p. 218

${ }^{55}$ Bastiat (1850 [2009]), p. 199.
} 
constructivismo racionalista que niega un orden en el aparente caos del crecimiento natural y evolutivo.

La ciudad de la antigüedad y del medioevo nació de la interacción de las distintas acciones humanas aun cuando pudiera parecer que no fuese así y eso otorgó a las ciudades un especial dinamismo. Como dice Fernando Chueca Goitia ${ }^{56}$ «La mayoría de las nuevas ciudades surgió, bien como desarrollo de antiguas aldeas o poblados indígenas, bien como consolidación de antiguos campamentos militares y colonias de veteranos, bien por ampliación de ciertas grandes propiedades rústicas.»

Algunas de estas soluciones espontáneas de la antigüedad se han revelado como más eficientes que las planificadas y han acabo siendo «redescubiertas» a lo largo de los años por los diseñadores de la ciudad. Este es el caso por ejemplo del adarve árabe. El adarve era, dentro de la ciudad islámica, una calle privada sin salida que daba acceso a varias viviendas y que incluso a veces se cerraba para mantener la privacidad de la misma. Este concepto, surgido espontáneamente, desapareció con la planificación de las ciudades y volvió a aparecer con la ciudad-jardín. En palabras de Fernando Chueca Goitia: «El adarve no tiene salida, no tiene continuación, no sirve un interés público, sino un interés privado, el del conjunto de casas en cuyo interior penetra para darles entrada. Es, por tanto, una calle privada que de hecho se cerraba de noche, aislando y protegiendo una pequeña comunidad de vecinos». "Solo volverán a renacer en algunas urbanizaciones modernas tipo de las ciudad-jardín donde predomina también el sentimiento de lo domestico y de lo privado ${ }^{57}$. Robert E. Dickinson: «Estas ciudades sin plano, amasijo de edificios y casas, con calles llenas de vida que varían en anchura y de dirección y se ramifican saliendo de otras principales para terminar en culs de sac, estas ciudades son típicas de España.» ${ }^{58}$

Obviamente esta no es más que una de las infinitas soluciones de las que nos puede proveer la convivencia de las personas en una ciudad libre y en la que se respeta el derecho de propiedad.

\footnotetext{
56 Chueca Goitia (2004), p. 58.

57 Chueca Goitia (2004), p. 76.

58 Chueca Goitia (2004), p. 73.
} 
El patio canario, el patio andaluz, las viviendas de anchos muros y paredes anchas, las cubiertas planas y a varias aguas, los aljibes, etc., son muchos de los inventos eficientes que el pasado nos ha legado. Un listado de las soluciones urbanas habituales con las que nos dota el planeamiento deviene ridícula en comparación con las posibilidades que otorgaría la interacción libre de los ciudadanos en una sociedad que respete los derechos de propiedad.

La entrega de un pasado en forma de tradiciones, en su más concreto origen etimológico, solo puede realizarse gracias a otro tipo de instituciones como son la familia, los oficios, la religión o la universidad, etc. Tanto la costumbre, como la moral, así como las tradiciones necesitan los cauces de información que se habían vertebrado a sí mismos. Si cada una de estas instituciones no tiene consciencia de sí misma y de sus funciones estaremos lejos de permitir que el caudal de conocimiento que se nos transmitía pueda llegar a generaciones venideras. Las universidades adolecen de una falta de transmisión transversal de las costumbres arquitectónicas y urbanísticas y en su afán de innovar parecen haber ignorado que toda innovación nace del pasado. «Liberándonos de aquella actitud que considera toda tradición como sacrosanta ${ }^{59}$ pero rescatándola cuando no es mejorada, complementándola cuando es perfeccionable y abandonándola cuando deja de serlo, pero siempre apoyándonos en ella. Así pues gran parte del legado urbanístico y arquitectónico del pasado ha quedado ignorantemente relegado en las universidades a asignaturas no transversales. Es de vital importancia recuperar un urbanismo y una arquitectura innovadores pero desde el pasado y desde la bondad de la costumbre y de lo propio del lugar. Recordemos que «lo que transforma el cerebro en mente no es sino la asimilación de una tradición. Esto significa que no podemos partir de nuevo, que debemos servirnos de lo que se ha hecho antes de nosotros. Un hecho que con frecuencia no ha sido comprendido adecuadamente por los racionalistas ingenuos, para los cuales existe un "yo puro" preexistente a la relación con el otro.» ${ }^{60}$

\footnotetext{
${ }^{59}$ Infantino (2000), p. 107.

${ }^{60}$ Infantino (2000), p. 104.
} 
Es verdad que un crecimiento espontáneo de la ciudad actual diferiría mucho del crecimiento espontáneo de la ciudad medieval o de la islámica. El progreso tecnológico ha traído consigo un desarrollo vertiginoso y unas velocidades de ejecución que poco tienen que ver con las de épocas antiguas. No obstante en términos cualitativos las semejanzas son muchas y las diferencias obedecen en la mayoría de ocasiones a leyes que no somos capaces de percibir por la complejidad del orden espontáneo. Muchos pueblos de la península ibérica nacieron al abrigo de un monasterio que en un principio buscó la soledad junto al cauce de un río. Su prosperidad atrajo el asentamiento paulatino de viviendas y finalmente la creación de poblaciones. Algo similar ocurre hoy en día. Centrales nucleares o térmicas, multinacionales, etc., equivalen a los monasterios de la antigüedad y junto a ellos prosperan pequeñas industrias que les dan servicio o se nutren de su mejora económica. Esta similitud esconde una mayor, la de la característica irreducible de la acción humana, la de las leyes de la lógica humana a la hora de ejercer la función empresarial. La evolución ya se ha encargado de diseñar mecanismos que permitan asimilar el crecimiento acelerado.

¿Cómo es la ciudad hoy en día? ¿Podemos extrapolar un orden espontáneo que pudo ser eficiente en el pasado al futuro? Cualquier comentario sobre la ordenación de una ciudad está ya fuertemente condicionado por la obligatoriedad de edificar dentro de ella, con un espacio disponible muy escaso y con sus correspondientes repercusiones económicas. El planeamiento falla por su ineficiencia a lo hora de intentar evitar las externalidades.

IX

\section{OTROS ASPECTOS A TENER EN CUENTA}

\section{La moral}

La vulneración de los principios que deberían regir nuestro comportamiento es escasas veces objeto de crítica en una sociedad finalista y relativista como la actual. Las virtudes morales deben estar arraigadas para mantener en estas condiciones una sociedad 
sin corrupción. Y desafortunadamente estamos lejos de la excelencia moral. Una sociedad que permita el libre intercambio y que respete la propiedad privada limita drásticamente la corrupción puesto que, por un lado, disminuyen enormemente las situaciones potenciales en la que esta se produce y, por otro, es el entorno en el que pueden nacer los principios de convivencia que son necesarios para el progreso mutuo. Veamos dos ejemplos comunes en el ámbito del urbanismo:

- Corrupción por recalificación del suelo y adquisición: en una sociedad libre y con protección de la propiedad privada no hay posibilidad de recalificación ya que en cualquier suelo puede desarrollarse cualquier proyecto que no infrinja la ley y los derechos de los demás. Por otro lado la propiedad privada y su gestión permite tener una conciencia del valor de las cosas y de las personas favoreciendo así el desarrollo de una ética social.

- Prevaricación por licencia ilegal: estamos en un caso similar al anterior. Una licencia pretende otorgarte derechos. Los derechos, sin embargo, te son propios y en una sociedad libre no debería de haber un órgano director que te otorgase derechos sino que, en todo caso, te los protegiese.

El sistema socialista crea las bases para que un mercado paralelo de la corrupción se establezca. Por un lado, mina la transmisión de conocimiento de una generación a otra. Por otro, relativiza la ley y la moral. Finalmente crea instituciones artificiales que chocan con la visión empresarial del hombre. La naturaleza humana es la que es y su lógica empresarial innata no puede modificarse por los deseos de las personas. La capacidad emprendedora se adaptará al entorno y se ejercerá también en ámbitos donde la moral no impera. Pedir que el ser humano sea ético es algo deseable, sin duda, pero no es algo que pueda decidirse de un día para otro. La moral es un hecho complejo que necesita de unas instituciones y de unos cauces culturales para transmitirse y evolucionar que deben cuidarse y protegerse. Crear un sistema artificial que deja en manos de las personas la custodia de importantes intereses en el que los mecanismos de mercado y de 
propiedad quedan maniatados es cuando menos temerario. La actividad corruptora que se produce «es de tipo defensivo, pues actúa como una verdadera "válvula de escape" y permite una cierta minoración del daño social que genera el socialismo.» ${ }^{61}$

\section{Las infracciones urbanísticas}

A algunas infracciones urbanísticas les ocurre algo similar a lo que a la economía sumergida. El planeamiento dicta normas y con ellas decide lo que se puede y no puede construirse en un lugar determinado al margen de las necesidades de su propietario. Ya hemos dicho que es incapaz de hacer el cálculo económico porque, entre otras cosas, no conoce las necesidades subjetivas del propietario. El problema, o la solución, es que superado cierto umbral de necesidad y después de calibrar el ratio costebeneficio en función de las multas por infracción que pudiera recibir, el propietario decide ampliar la vivienda en un dormitorio que necesita, infringiendo así la normativa vigente. En las nuevas urbanizaciones de viviendas unifamiliares afloran las construcciones ilegales ya que las familias necesitan espacio para vivir que la normativa les impide desarrollar. Es sencillo ver como la administración en lugar de perseguir a estas personas debería percatarse de que probablemente su normativa es excesivamente restrictiva y no permite que las familias crezcan en un hogar acorde a sus necesidades. La infracción vuelve a ser esa «válvula de escape» a una normativa impuesta por un poder centralizado. «La aparición, por tanto, de una sociedad o economía oculta, sumergida o "irregular" es una característica inseparable del socialismo». ${ }^{62}$ Por lo tanto, lejos de ser algo a desterrar, es un síntoma que permite detectar que el mercado requiere de otras condiciones para funcionar. En lugar de condenar e intentar evitar la economía sumergida del urbanismo que son las infracciones, deberían de analizarse sus canales de funcionamiento y las condiciones en las que se desarrolla porque es por ahí por donde nos está

\footnotetext{
${ }^{61}$ Huerta de Soto (2010), p. 120.

62 Huerta de Soto (2010), p. 124.
} 
mostrando que las personas son capaces de colaborar de forma empresarial.

\section{Retraso tecnológico}

En lo que a la lentitud para innovar se refiere, la intervención estatal produce un importante efecto. Las limitaciones en el empleo de determinados materiales, la limitación de la propia función mercantil en el campo de la edificación, la expansión crediticia que aportaba beneficios sin necesidad de competir ni de innovar, etc., han hecho del mercado de la edificación y del urbanismo uno de los mercados con menor innovación tecnológica. Mientras que sectores como la aeronáutica, la automoción o la informática y las telecomunicaciones han aportado grandes avances, la edificación y el urbanismo no lo han hecho y cuando han evolucionado ha sido en aplicación de innovaciones de otros sectores.

\section{REFERENCIAS BIBLIOGRÁFICAS}

Anderson, Terry L. y Leal, Donald R. (1993): Ecología de mercado. Madrid: Unión Editorial.

Chueca Goitia, Fernando (2004): Historia del urbanismo. Madrid: Alianza Editorial.

HAYEK, Friedrich von (1988 [2000]): La fatal arrogancia. Citado por: Infantino, Lorenzo. «El orden sin plan». (2000). Madrid: Unión Editorial.

- (1960 [2008]): Los fundamentos de la libertad. Madrid. Unión Editorial.

HuERTA DE SOTO, Jesús (2004): «La teoría de la eficiencia dinámica». Procesos de Mercado. Vol. 1, n.․․ 1. Unión Editorial.

- (1992 [2010]): Socialismo, cálculo económico y función empresarial. Madrid. Unión Editorial.

INFANTINO, Lorenzo (2000): El orden sin plan. Madrid: Unión Editorial.

Martínez Meseguer, César (2009): Teoría evolutiva de las instituciones. Madrid: Unión Editorial. 
Menger, Carl (1871 [1997]): Principios de economía política. Madrid: Unión Editorial.

Mises, Ludwig von (1949 [2007]): La acción humana. Madrid: Unión Editorial.

- (1957 [2010]): Teoría e historia. Madrid: Unión Editorial.

- (1944 [2005]): Burocracia. Madrid: Unión Editorial.

SALIN, Pascal (2000[2008]): Liberalismo. Madrid: Unión Editorial. LeONI, Bruno (1961 [1995]): La libertad y la Ley. Madrid: Unión Editorial. 